ного периода ( $p=0,005$ и $p=0,03)$, CCL15 - на 4 -е и 7-е сутки ( $p=0,05$ и $p=0,02)$. В противоположность этому у пациентов ИМОКА определялось большее повышение уровня CXCL12 при поступлении $(p=0,04)$.

Выводы. По результатам исследования с использованием мультиплексного анализа у пациентов с ИМБОКА и ИМОКА выявлены различия в содержании провоспалительных и провоспали- тельных цитокинов. Несмотря на сопоставимое повышение в сыворотке крови у пациентов обеих групп цитокинов CCL-26, CCL-5, CCL-8, CCL-13, CCL-26, большее повышение содержания в сыворотке крови у пациентов ИМБОКА определено по провоспалительным цитокинам IL-16, CCL-21, IL-20, CCL-15, а также CXCL-12, LIF, TPO, SCF, которые обладают противовоспалительной и регенераторной активностью.

DOI $10.52727 / 2078-256 X-2021-17-3-61-62$

\title{
ИЗМЕНЕНИЕ ПРОДУКЦИИ АКТИВНЫХ ФОРМ КИСЛОРОДА ТРОМБОЦИТАМИ В ГЕНЕЗЕ ИХ НЕДОСТАТОЧНОГО ОТВЕТА НА АНТИТРОМБОЦИТАРНУЮ ТЕРАПИЮ ПРИ КОРОНАРНОЙ РЕВАСКУЛЯРИЗАЦИИ
}

\author{
М.Д. Гончаров ${ }^{1,2}$, Ю.И. Гринштейн ${ }^{2}$, А.А. Савченко ${ }^{2}$, А.А. Косинова ${ }^{2}$ \\ ${ }^{1}$ Федеральный центр сердечно-сосудистой хирургии, Красноярск, Россия \\ ${ }^{2}$ Красноярский государственный медииинский университет им. проф. В.Ф. Войно-Ясенеикого \\ Минздрава России, Красноярск, Россия
}

Цель. Изучить влияние коронарного шунтирования (КШ) и антиагрегантной терапии на синтез активных форм кислорода (АФК) тромбоцитами пациентов с ишемической болезнью сердца (ИБС) в зависимости от их чувствительности к ацетилсалициловой кислоте (АСК).

Материал и методы. Обследован 101 пациент с ИБС. Прием антиагрегантов прекращался минимум за 5 дней до КШ. После КШ 63 пациента получали терапию АCK, 38 - терапию АСК и клопидогрел. Контроль - 36 здоровых добровольцев. Забор крови проводили до начала антиагрегантной терапии (до и в 1-е сутки после КШ) и на фоне терапии (8-10-е сутки после операции). Резистентность к АСК определяли на оптическом агрегометре при уровне агрегации тромбоцитов с арахидоновой кислотой $\geq 20 \%$ на фоне приема АСК либо после предварительной 3-минутной инкубации in vitro с 3,36 мМоль АСК до начала приема АСК. Пациента относили к резистентному, если устойчивость определялась хотя бы в одной из трех точек измерений. Для изучения продукции АФК исследовали спонтанную и АДФ-индуцированную хемилюминесценцию (ХЛ) тромбоцитов с люминолом и люцигенином на биохемилюминесцентном анализаторе. Оценивали максимальную интенсивность ХЛ $\left(I_{\max }\right)$, время выхода на максимум ХЛ $\left(T_{\max }\right)$ и площадь под кривой ХЛ $(S)$. Усиление индуцированной АДФ ХЛ определяли отношением $S$ индуцированной АДФ ХЛ к $S$ спонтанной ХЛ и обозначали как индекс активации (ИА).

Результаты. Выявлено 30 резистентных к ACК пациентов с ИБС (pАCK) $(17$ - на те- рапии АCK, 13 - на терапии АCK и клопидогрел). По сравнению с контрольной группой у чувствительных к АСК пациентов с ИБС (чАСК) во всем периоде наблюдения значения показателей ХЛ тромбоцитов были выше, у рАСК (АСК) до КШ увеличено $T_{\max }$ с люминолом (АДФ-индуцированный тест) и люцигенином (спонтанный тест), а у рАСК (АСК и клопидогрел) в 1-е и на 8-10-е сутки после КШ повышены $I_{\max }$ в спонтанных и АДФ-индуцированных тестах с люминолом и люцигенином, в 1-е сутки после КШ повышены $S$ в спонтанном тесте с люминолом и ИА с люцигенином. По сравнению с чАСК в группе рАСК (АСК) до и в 1-е сутки после КШ снижена $I_{\max }$, а на 8-10-е сутки $S$ в тесте с люцигенином в группе рАСК (АСК и клопидогрел) снижен ИА в тесте с люцигенином в 1-е сутки после КШ. До КШ $S$ в индуцированном тесте с люминолом выше в группе pACK (АСК и клопидогрел) по сравнению с группой рАСК (ACK). У чАСК по сравнению с периодом до КШ в 1-е сутки после КШ снизились $S$ в АДФ-индуцированном тесте с люминолом и $T_{\max }$ в АДФ-индуцированном тесте с люцигенином и повысилась $I_{\max }$ в спонтанном тесте с люцигенином, а к 8-10-м суткам после операции повысились $S$ в спонтанном и АДФ-индуцированном тесте с люминолом и ИА с люцигенином. В группе рАСК (АСК) на 8-10-е сутки после операции снизилась $S$ в АДФ-индуцированном тесте с люцигенином по сравнению с периодом до КШ.

Заключение. Продукция АФК тромбоцитами в зависимости от их чувствительности к АСК 
носит разный характер. Тромбоциты чАСК пациентов с ИБС синтезируют высокие уровни первичных и вторичных АФК как в состоянии покоя, так и при стимуляции, а КШ частично снижает уровень АФК в первые сутки после операции с увеличением синтеза на 8-10-е сутки по сравнению с исходным уровнем. Продукция АФК тромбоцитами рАСК (АСК) находится ниже, чем у чАСК на уровне контрольной группы, а рАСК (АСК и клопидогрел) выше, чем в контрольной группе, на уровне чАСК. Прием только АСК снижает индуцированную продукцию АФК по сравнению с исходным уровнем, а добавление клопидогрела к АСК позволяет сохранить высокую продукцию АФК в тромбоцитах у рАСК, как у чАСК.

DOI $10.52727 / 2078-256 X-2021-17-3-62-63$

\title{
ОПИСАНИЕ КЛИНИЧЕСКОГО НАБЛЮДЕНИЯ РЕЦИДИВА ТЭЛА ПОСЛЕ ПРЕКРАЩЕНИЯ ДЕВЯТИЛЕТНЕЙ ТЕРАПИИ ВАРФАРИНОМ
}

\author{
Д.Х. Каримова, Н.Е. Чапова \\ ФГАОУ ВО «Первый Московский государственный медицинский университет им. И.М. Сеченова» \\ Минздрава России (Сеченовский университет). Кафедра факультетской терапии № 1 \\ им. В.Н. Виноградова, Институт клинической медицины им. Н.В. Склифосовского \\ Сеченовского университета, Москва, Россия
}

Введение. Среди причин острых сердечнососудистых катастроф венозные тромбоэмболические осложнения (ВТЭО), включающие тромбоз глубоких вен и тромбоэмболию легочной артерии (ТЭЛА), занимают третье место в мире. Своевременная диагностика ТЭЛА бывает затруднительной, в связи с чем особое значение приобретает как первичная, так и вторичная профилактика этого грозного клинического состояния. В настоящее время хорошо известны и категоризированы факторы риска (ФР) развития ТЭЛА, еще остаются вопросы в отношении ее вторичной профилактики в ситуациях, когда отсутствуют идентифицированные ФР.

Описание клинического случая. Пациентка С. длительно страдала артериальной гипертензией, сахарным диабетом II типа и ожирением I степени, постоянно принимала антигипертензивную терапию с достижением целевых значений артериального давления (АД). В декабре 2010 г. (в возрасте 76 лет) в связи с внезапно возникшей одышкой и ощущением дискомфорта в грудной клетке больная была экстренно госпитализирована в клинику Факультетской терапии № 1 Сеченовского университета. При компьютерной томографии (KT) легких с внутривенным контрастированием выявлена массивная ТЭЛА: множественные дефекты контрастирования практически во всех сегментарных (до субсегментарных уровней) легочных артериях обоих легких. После проведенного лечения на протяжении последующих 9 лет пациентка продолжала прием варфарина с достижением целевых значений МНО в диапазоне от 2 до 3, на фоне чего ее состояние оставалось удовлетворительным. В сентябре 2019 г. в связи с подго- товкой к плановой операции (факоэмульсификация катаракты) терапия варфарином была отменена и после оперативного вмешательства не возобновлялась. Состояние больной оставалось стабильным на протяжении трех месяцев, когда появились выраженная одышка и ощущение дискомфорта в грудной клетке. На ЭКГ впервые в жизни регистрировалась фибрилляция предсердий, пациентка была госпитализирована в Сеченовский университет. При проведении КТ легких с контрастированием обнаружена двусторонняя ТЭЛА, а ультрозвуковая допплерография сосудов нижних конечностей показала картину острого флотирующего тромбоза бедренной вены слева с проксимальной границей тромба на 25-30 мм дистальнее слияния бедренной вены и глубокой вены бедра. В клинике проводилась терапия: клексаном, эналаприлом, индапамидом, бисопрололом, аторвастатином, омепразолом. В дальнейшем клексан был заменен на апиксабан в стандартной дозе 10 мг/сут, остальная терапия оставалась без изменений. $\mathrm{K}$ настоящему времени пациентка почти 2 года продолжает прием антикоагулянтной терапии апиксабаном, состояние остается удовлетворительным, ТЭЛА не рецидивировала.

Обсуждение. Антикоагулянтная терапия является одной из основных составляющих тактики ведения пациентов, ранее перенесших ТЭЛА, поскольку позволяет надежно предотвратить возникновение рецидивов. На сегодняшний день нет единого подхода в отношении ведения пациентов с ТЭЛА, развившейся в отсутствие ФР ВТЭО. Рекомендуется обсуждать продолжение антикоагулянтной терапии на неопределенный период времени (класс рекомендаций $-2 \mathrm{a}$; 